urine was very dark coloured, and rather scanty in amount; the gluteal muscles very rigid; no sweating at any time. She ate a bran mash, and appeared perfectly quiet and sleeping until about 9.30 P.M., when she suddenly went down, and had attacks of intermittent convulsive struggles, and continued in these for the night; she received chlorodyne $\ddot{3} \mathrm{ij}$., which had a quietening effect.

The urine was very scanty in amount, the bowels fairly free. Next day she received tinct: colchici $\bar{j} \mathrm{ij}$., which had the effect of increasing the amount of urine, but that was still dark in colour.

It was decided to place her in slings, which was accomplished after some difficulty; but she made good use of them, and fed fairly well on bran mashes. Another dose of colchicum was administered, and pot. nit. 3ij., twice a day, given in the feed; she gradually improved, the urine became clear, and normal in amount, the subsequent treatment consisting of nux. vomica ji. twice a day. She was taken out of the slings on I 5 th January, walked quite well, but unfortunately got down in the stall at night, which was rather small for her, and could not get up. She was again placed in slings, and two days after was sent home apparently all right, and has continued so since.

Remarks. - In the treatment of cases of this affection, characterised by great cerebral disturbance and riolent convulsions and struggling, it is of importance to decide what course to adopt to relieve these distressing symptoms. In some of the cases marked by great violence, which renders the handling of the patient dangerous, it is clear that attempts must be made to promote quietude, as otherwise the animal will wear itself out.

It is evident in such cases that both the cerebrum and the spinal cord become affected by whatever produces the disease; we know from experience that opium and its salts are of no value in relieving the convulsive fits - in fact they often increase them; acting on the bowels or on the kidneys will not succeed in preventing them in severe cases; theoretically speaking, narcotics may be said to be contra-indicated, but there is no denying the fact that narcotics such as cannabis indica or chloral hydrate give very beneficial effects in such cases, in the way of keeping the patient quiet, and preventing him injuring himself or the attendants, even though a successful issue may not be brought about.

With regard to the kidneys, it often occurs that the secretion of urine is deficient, and when this is the case the administration of colchicum is of the greatest benefit.

\title{
CLINICAL NOTES.
}

By Vet.-Lieut. Butcer, Army Veterinary School, Aldershot.

(I.) A young horse was said to have injured its leg by kicking the stall post. On examination the limb was pendant, the foot hot, the patient very nervous and evidently in great pain. The foot was fomented, and in a few days the animal walked well and trotted nearly sound; for some unknown reason, however, I did not feel satisfied with its progress, and twice examined and searched the foot carefully, but beyond the cxistence of slight heat could detect 
nothing abnormal. Three weeks subsequent to admission there was still slight heat of the wall, the horse moving very nearly sound; it was now seen, however, that a small bead of serum was present at the coronet. The sole was immediately removed, and the sensitive sole was found gangrenous, a slough of 2 square inches coming away, and the whole of the horny sole and frog being detached. The case recovered rapidly.

Remarks. - The comparative soundness of the case was deceptive, and although the previous examinations of the foot were very thorough, they were not sufficiently so, and the result was very nearly a disaster.

(2.) An aged mare was sent for treatment for a slight purulent discharge from the near nostril, which had been noticed at intervals for the past twelve months. Operation had been recommended, but the owner objected and a blister had been applied over the region of the facial sinuses. On the case being sent to me, the animal having meanwhile changed hands, I opened both sinuses on the left side, and found a small quantity of foetid pus in the maxillary sinus, and a considerable thickening of the septum between the upper and lower cavities.

The discharge ceased for three weeks and then recommenced, being of small amount and always from the left nostril. I examined the teeth and found that the fourth upper left molar was slightly depressed, and that the central portions of its wearing surface were much darker than those of its fellows.

After much hesitation I decided to extract this tooth, and in doing so it fractured transversely at the neck, necessitating the use of the trephine and punch to remove the fangs. The case made a rapid recovery.

Two years subsequently I again met this animal, whose then owner informed me that prior to his purchasing it some operation had been performed on its face, but that it had not suffered since, though within three days of this communication there was a discharge from the seat of the trephine wound over the tooth cavity, which was due to the passage of food upwards.

Remarks.-The tooth that was extracted was found, on being split, to have within its interior large cavities filled with the débris of food.

This is not an uncommon condition, as an examination will speedily show. In many molar teeth there will be noticed on the table small black spots, from which may readily be picked out portions of food, and on the tooth being split cavities of greater or less extent and likewise filled with food débris will be revealed. This condition, I repeat, is common, and the question is, how far is it a source of trouble? The curious cavities in the particular instance under notice reached four-fifths of the entire length of the tooth, and although so voluminous their entrance on the table was not of larger circumference than would admit a pin, and undoubtedly increased the difficulty of extraction by rendering it brittle.

(3.) A ten-year-old mare, on being ridden 500 yards at a walk, dropped dead. She had been a fretful animal, but had never suffered from any form of illness except that when in strong work she was troubled with diarrhoea, and she always carried a good coat and capital condition. The day was extremely hot, and it had been preceded by very cold weather. 
Post-mortem Examination.-Dilatation with atrophy and fatty degeneration of the heart; the organ generally very thin, and when emptied even the walls of the left ventricle collapsed flat; the aortic semilunar valves were extremely thin, greatly stretched, and slightly frayed at their edges, and the corpora Arantii had entirely disappeared. The muscular tissue of the organ was very friable, and microscopically showed extensive fatty metamorphosis.

Remark.-Supposing one had been called upon to examine this animal as to soundness on the previous day!

\section{INTERESTING CASES.}

By Thomas Walley, M.R.C.V.S., Principal of the Royal Veterinary College, Edinburgh.

\section{INTRA-MURAL CARDIAC ABSCESS IN A COW.}

ON the 8 th of February I received from Mr D. C. Smith, M.R.C.V.S., New Cumnock, the heart of a cow, and on examination I found projecting from the ventricular septum into the right ventricle an eminence having the shape of an English cottage loaf and measuring 3 inches in diameter, by 2 inches in depth from its summit to the level of the ventricular surface of the septum. The endocardium had been entirely removed (by softening and the current of blood) from its salient parts, and in its place were several layers of coagulated lymph. On making an incision into the tumour, which was of a fluctuating character, a quantity of thick creamy pus escaped. (Plate VI., Fig. 2.) It was odourless, and after its evacuation a very large cavity was left in the substance of the septum, which, however, was intact on the side of the left ventricle. No other departure from the normal existed in the walls of the heart, except that there was slight hypertrophy, or in the valves.

History. - Mr Smith was asked to make a post-mortem examination of the cow on the previous Saturday, she having died suddenly on the morning of that day. She had shown no symptoms of illness until about a week previously, and these symptoms were not of such a character as to lead the owner to suppose that there was anything materially wrong with her. All the other organs were, Mr Smith informed me, healthy.

Failing to find any evidence of the penetration of a foreign body or of any general myocarditis, I came to the conclusion that the abscess must have had a pyæmic origin, and on writing to $\mathrm{Mr}$ Smith for further information he replied that " the cow was bred by her owner, and previously to the spring of I 893 had been perfectly healthy. At that time she suffered from what the owner described as 'Foul in the Foot,' which had given rise to feverish symptoms for a few days at the commencement of the attack, and the foot was not perfectly healed until after the lapse of three months." This, in my opinion, pointed, as I had suspected, to the pyamic origin of the abscess.

The cause of death was probably syncope. 